\title{
Is “Chronic Kidney Disease” a Disease?
}

\section{Authors}

1. Benjamin T H Smart, PhD. Senior Lecturer.

Department of Philosophy

Auckland Park Campus

University of Johannesburg

Johannesburg, 2006

2. Richard J Stevens, PhD. Associate Professor.

Nuffield Department of Primary Health Care Sciences, University of Oxford.

Radcliffe Observatory Quarter, Woodstock Road, Oxford. OX2 6GG

2. Jan Y Verbakel, MD. PhD. Senior Clinical Researcher.

Nuffield Department of Primary Health Care Sciences, University of Oxford

Radcliffe Observatory Quarter, Woodstock Road, Oxford. OX2 6GG

\section{Corresponding author:}

Benjamin Smart

Department of Philosophy

Auckland Park Campus

University of Johannesburg

Johannesburg, 2006

Email address: bsmart@uj.ac.za

Telephone number: +27 799985981

Running Title: Is “Chronic Kidney Disease” a Disease?

Keywords: Chronic Kidney Disease; Concepts of Disease; Biostatistical Model; Boorse; Harmful Dysfunction; Naturalism; Overmedicalization 


\section{Abstract}

Several philosophers of medicine have attempted to answer the question 'what is disease?' In current clinical practice an umbrella term “Chronic kidney disease” (CKD) encompasses a wide range of kidney health states from commonly prevalent sub-clinical, asymptomatic disease to rare end-stage renal disease requiring transplant or dialysis to support life.

Differences in severity are currently expressed using a 'stage' system, whereby stage 1 is the least severe, and stage 5 the most. Early stage CKD in older patients is normal, of little concern, and does not require treatment. However, studies have shown that many patients find being informed of their "chronic kidney disease” distressing, even in its early stages. Using existing analyses of disease in the philosophy literature, we argue that the most prevalent diagnoses of CKD are not, in fact, diseases. We conclude that, in many diagnosed cases of CKD, diagnosing a patient with a "disease” is not only redundant, but unhelpful.

\section{Introduction}


The conceptual analysis of 'disease' has been a core component of the philosophy of medicine since the mid-1970's. ${ }^{1-7}$ Some have argued that the debate is of great importance, since notions of health and disease feed into clinical decision-making, the assessment of moral and legal responsibility, the right to medical treatment, and eligibility for disability allowance. ${ }^{8}$ Germund Hesslow, however, claims that although the concept of disease might be useful in some contexts, it is redundant in medical practice. He claims that 'Diseases are to clinicians what gardens are to gardeners or cars are to garage mechanics. These terms are handy to point to a certain area of competence, but the gardener does not need a definition of "garden" to help him decide what to do about plants on a balcony and the car mechanic does not need a definition of "car" to be able to decide if he should try to fix a lawnmower." 9(13) Hesslow may be right about the concept's role (or rather, lack thereof) in prognosis and treatment, but 'disease' is nevertheless a term deeply entrenched in modern medicine. In this paper we demonstrate why the work of philosophers in this field should be deemed salient by medical policy-makers, and a fortiori relevant to clinical practice.

Clinicians are trained to identify diseases, and are usually bound to inform patients of their illness once diagnosis is possible. ${ }^{10}$ The problem of 'too much medicine' in the West (which includes, but is not restricted to, overdiagnosis and over treatment) is widespread, however, and since being informed that one is diseased can have significant emotional and physiological effects on patients, the clinician must tread carefully. We take the problems faced by clinicians in this regard to be, at least in part, a consequence of non-disease states being classified as diseases.

In this paper we consider how defining disease can, and indeed should, have a substantial effect on which physiological states are identified as diseases (and hence which physiological states warrant troubling a patient, in this way). We focus on the states currently termed stages 
of Chronic Kidney Disease (CKD), and demonstrate that careful consideration of philosophical concepts of disease suggests that the existing stage-based classification strategy should be abandoned.

CKD encompasses a wide range of kidney health states from commonly prevalent subclinical, asymptomatic disease to rare end stage renal disease requiring transplant or dialysis to support life. Differences in severity are currently expressed using a ‘stage’ system, whereby stage 1 is the least severe and stage 5 the most. Early stage CKD in older patients is normal, of little concern, and does not require treatment (even stages 3 and 4 are often left untreated in the elderly. ${ }^{11}$ However, giving an individual a disease label is not necessarily harmless: this is evidenced in the specific case of CKD by studies showing patients become distressed when informed that they suffer from CKD, even in its early stages. ${ }^{12}$ Using existing analyses of disease in the philosophy literature, we argue that the most prevalent stages of CKD are not, in fact, diseases.

In section 2 we outline the nature of CKD, and what demarcates its various stages. We also present the results of some recent trials, demonstrating the problems associated with diagnosing patients with early stage CKD. In section 3 we present a number of philosophical analyses of disease. Each analysis has been subject to a number of (often warranted) objections, but we do not attempt to address these issues here. Rather, we assume a strategy of reflective equilibrium - even if there is an analysis not subject to counterexamples, it is not necessary to identify it for the purposes of this paper. In section 4 we argue that early stage CKD does not qualify as a disease under any existing philosophical account of disease, and further suggest that it is unlikely to under any other viable candidate. We conclude that, in many cases of CKD, diagnosing the patient with a disease is not only a redundant and incorrect application of the concept, but a practice that should be avoided in order to maximise the wellbeing of patients. 


\section{Chronic Kidney Disease}

Here we outline the diagnostic criteria for the various stages of CKD, to enable us later to show how they fit into the available conceptual analyses of 'disease' and 'pathological condition'. The most widely endorsed concepts of disease take 'biostatistical normality' and/or 'harmfulness' to be necessary components. In table 1, then, we provide a basic outline of what demarcates the various stages of kidney disease in these terms.

While a variety of conditions and syndromes may affect the kidneys over either chronic or acute time frames, in 2002 guidelines from the US National Kidney Foundation proposed that the term 'chronic kidney disease' be reserved for specific dysfunctions of the kidneys (table 1), with emphasis on the glomerular filtration rate (GFR). ${ }^{13}$ The full spectrum of kidney diseases including acute kidney injury, diabetic nephropathy and many more are beyond the scope of this paper.

\section{Insert Table 1 Here.}

It is worth noting that the scheme above has been updated by subsequent guidelines for the US or modified for other countries, but the emphasis on GFR, or estimated (eGFR) calculated from markers in the blood, in the definition of CKD has remained constant.

In health care systems such as the UK, the most prevalent diagnosis of CKD is CKD stage 3, defined by GFR below $60 \mathrm{ml} / \mathrm{min} / 1.73 \mathrm{~m}^{2}$ (de Lusignan et al write that “A UK audit in 2012 estimated $90 \%$ of cases of CKD are stage 3 , and of these, $84 \%$ are stage $3 a^{{ }^{\prime 14}}$; ; and Hill et al that "CKD prevalence by stage was Stage-1 (eGFR>90+ACR>30): 3·5\% (2·8-4·2\%); Stage2 (eGFR 60-89+ACR>30): 3·9\% (2·7-5·3\%); Stage-3 (eGFR 30-59): 7·6\% (6•4-8·9\%);

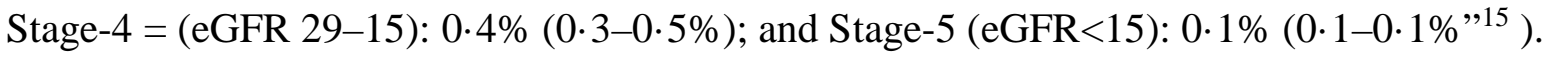


Unlike the late stages of CKD, especially stage 5, CKD stage 3 in general is asymptomatic. In our study of CKD as disease we will in particular contrast stage 5, the most severe, with stage 3, the most prevalent.

\section{Concepts of Disease}

Given the fundamental role disease plays in the medical sciences, it is hardly surprising that a large body of literature in philosophy is devoted to analysing the concept. The term 'disease', however, is employed in numerous distinct (although related) medical fields, including (but not restricted to) pathology, clinical practice, and public health. Here we outline the current popular analyses of disease, from both the pathologist's, and from the clinician's perspective, and explicate some of the relevant problems that accompany them. Responding to these issues, however, is beyond the scope of this paper. In section 4 we discuss how CKD fits in with the conceptual analyses outlined below.

\section{(i) The Pathologist's Concept of Disease - Boorse's Biostatistical Theory}

Pathology is the branch of medical science that describes the study of physiological subsystems (fluids, cells, tissues, organs) for the purpose of diagnosing, and establishing the cause(s) of, biological abnormalities; that is, pathologists examine samples of tissue/fluids (or perhaps an entire body) and attempt to identify abnormalities typical of specific diseases. It is this focus on discovering abnormalities that motivates the first kind of disease-concept: the biostatistical theories (BST). Christopher Boorse has spent 40 years defending this approach, and a similar strategy is adopted by Peter Schwartz. ${ }^{1,2,3,4,16}$ Here, a 'disease' is to be read as a 
'pathological condition', where a pathological condition is the 'theoretical' concept of disease employed by pathologists, as opposed to laymen, or perhaps even clinicians. ${ }^{5}$

Following various objections to Boorse’s original formulation, we shall consider only his revised 2014 version, ${ }^{4}$ which comprises 4 parts:

1. The reference class is a natural class of organisms of uniform functional design; specifically, an age group of a sex of a species.

2. A normal function of a part or process within members of the reference class is a statistically typical contribution by it to their individual survival [or] reproduction.

3. Health in a member of the reference class is normal functional ability: the readiness of each internal part to perform all its normal functions on typical occasions with at least typical efficiency.

4. A disease... is a type of internal state which impairs health, i.e., reduces one or more functional abilities below typical efficiency

Boorse thus takes a physiological subsystem to be diseased if and only if it performs its function subnormally (see figure 1) relative to the reference class to which the organism in question belongs (note that by 'subnormal', Boorse does not mean any state below the statistical mean. Where the line demarcating health and disease states gets drawn is unclear, however. One possibility is 'sufficiently below that average to render the system diseased', but this seems to beg the question - we shall not argue to the contrary, here).

\section{Insert Figure 1 here}


Most physiological subsystems have a 'natural function' ${ }^{1}$. That is, the subsystems $d o$ something specific that positively contributes to the health of the organism. Let us take figure 1 to represent the functional efficiency of kidneys for some reference class $R$. Some members of $R$ have healthy kidneys performing their function (of filtering the blood of waste products) very efficiently; whereas other members of $R$ have kidneys that barely function at all. These individuals fit into the far right, and far left-hand side of figure 1 respectively. The shaded area represents those kidneys performing their function subnormally (in Boorse's sense), that is to say, those members of $R$ with diseased kidneys. The areas to the right of the shaded area represent organs operating with normal (or, to the far right, supernormal) functional efficiency (for $R$ ). For a member of $R$ to be diseased with respect to some trait $T$, then, is just to fit into the shaded area of the chart representing $T$ for $R$. Since, as a population (of people sharing a reference class) ages, the average functional efficiency of organs/tissues/cells of that population tends to deteriorate, the degree of functional efficiency necessary for a member of that population to have healthy organs/tissues/cells decreases. Thus, according to BST, an elderly man and his son may have equally well-functioning hearts, yet the former's heart is healthy and the latter's diseased.

Numerous objections have been raised against BST, but they tend to be variants of the following two: first, there is the 'line-drawing problem' ${ }^{18}$, that is, the problem of deciding where one must draw the line that separates normal from subnormal part-function. Second, there is the objection that the notion of disease is inherently value-laden - that for some condition to be a disease, it must be a bad thing to have, and BST is explicitly naturalist (value-free). Schwartz, who also claims to provide a 'theoretical', value-free notion of disease, addresses the first issue (see below). We believe the second objection to be

\footnotetext{
1 There are vestigial physiological subsystems, such as goose-bumps, and possibly the appendix, but those shall be ignored for now.
} 
unproblematic for both Boorse and Schwartz, since Boorse is attempting a theoretical conception of disease, whereas value-ladenness only seems to be necessary (if, indeed, it is necessary) in a clinical context.

\section{Schwartz's Frequency and Negative Consequences Approach}

The line-drawing problem highlights the apparent arbitrariness of where the 'line' separating subnormal from normal efficiency of part-function lies. Schwartz's Frequency and Negative Consequences Approach (FNC) attempts to resolve this problem by adding a further component to the standard BST proposed by Boorse. He suggests that one must include a 'negative consequences' dimension, whereby negative consequences are 'effects that significantly diminish [the ability to] carry out an activity that is generally standard in the species and has been for a long period of time'. ${ }^{18(379)}$ He illustrates the position as follows (note that the dotted line must be read as lying on its own axis):

\section{Insert figure 2 here}

The benefit of this approach, it is argued, is that it maintains the naturalistic nature of the disease-concept (it remains value-free), whilst providing an objective standard for separating health and disease states. The problem, of course, is that it seems only to push the problem back. 'The ability to carry out a standard activity' is vague insofar as abilities come in degrees. Running is a standard activity for human beings (at least for non-elderly reference classes), but some healthy people run more effectively than others. At what 'ability' is one deemed no longer able to run; that is, unable to carry out this standard activity? On the face of it, at least, FNC is no more successful at avoiding arbitrary line-drawing as BST. 
The line-drawing problem is thus at least prima facie problematic for both BST and FNC. The basic idea, however, that disease is a matter of subnormal part-function, where the class of subnormal functioning physiological subsystems has a negative impact on the capabilities of an organism, seems plausible enough. In section 4 we consider how CKD fits into the BST and FNC concepts of disease. Next, however, we turn our attention to the second kind of conceptual analyses of disease: those that take disease to be an inherently value-laden notion.

\section{(ii) The Clinician's Concept of Disease}

In order to highlight the distinction between Boorse's theoretical concept of pathological condition, and the concept of disease generally employed by general practitioners, it is useful to separate the roles of 'patient-facing' clinicians and 'non-patient facing' pathologists. Let us take the term 'clinician' to imply a patient-facing role. In this way, the concepts useful to a clinician may be different to those of a pathologist. The pathologist's role is to examine tissue, cells, blood samples, and so on, in order to identify pathological abnormalities. In this way, she may be unaware of the specific complaints the patient has, and is concerned primarily with conducting the tests requested by the clinician. There is nothing in this process that directly refers to the patient's concerns, and this (one must assume) is why Boorse and Schwartz agree that the concept of pathological condition is value-free. None of this is true in clinical practice, however - typically, the very first task of the clinician is to listen to the patient's complaints. Thus, harm, discomfort, and stress, seem to be at the very core of clinical medicine, and from this perspective, at least, a fundamental part of the diseaseconcept. Here we outline three analyses of disease which take harm to be essential to disease.

\section{(a) Wakefield's Disease as Harmful Dysfunction}


Jerome Wakefield provides an account of disease as harmful dysfunction, whereby the function of a physiological subsystem has an etiological base; that is, the function of an organ, tissue, or cell, is whatever explains its presence in the organism, following the evolutionary process. He outlines his concept of 'disorder' as follows:

A condition is a disorder if and only if (a) the condition causes some harm or deprivation of benefit to the person as judged by the standards of the person's culture (the value criterion), and (b) the condition results from the inability of some internal mechanism to perform its natural function, wherein a natural function is an effect that is part of the evolutionary explanation of the existence and structure of the mechanism (the explanatory criterion)..$^{7(384)}$

Wakefield's view accommodates the intuition that health and disease states have something to do with the functional efficiency of biological parts, but includes the prima facie important normative qualities missing in the BST and the FNC (note that neither biostatistical conception were targeting a clinical definition of disease, so the fact that the inclusion of harm or deprivation is necessary for the clinical concept is neither an issue for Boorse nor Schwartz).

Schwartz, however, has argued that Wakefield's account is flawed, since it, like the BST, fails to resolve the line-drawing problem. Since the explanatory condition of Wakefield's account is grounded by dysfunction and an etiological account of natural function, Wakefield must be able to provide an etiological account of dysfunction for all diseases, in order for his view to be consistent. This is not possible, however, for acquired conditions, since they are neither favoured nor not-favoured by natural selection. ${ }^{16(370)}$ Smart has argued, however, that a similar approach to Wakefield's can avoid this problem. 


\section{(b) Smart's Disease as Harmful Function}

The objection to Wakefield's account comes about because (i) he needs an account of dysfunction, and (ii) he is committed to this account being grounded by evolution. Smart avoids this problem by denying that 'dysfunction' must play a role in the disease-concept. ${ }^{5}$

The explanatory criterion provided by Wakefield provides information about what the natural function of a physiological subsystem is. The existence of kidneys in human beings, for example, has an evolutionary explanation in the form of a need for glomerular filtration. The normal GFR range is $90-120 \mathrm{~mL} / \mathrm{min} / 1.73 \mathrm{~m}^{2}$, but that is not to say one cannot state that a patient's kidney is performing its function when her GFR is $80 \mathrm{~mL} / \mathrm{min} / 1.73 \mathrm{~m}^{2}$, it simply implies that her kidney is performing its function less efficiently than the degree of efficiency which explains its continued existence through the evolutionary process (GFR 90-120 $\mathrm{mL} / \mathrm{min} / 1.73 \mathrm{~m}^{2}$ ). With this in mind, Smart provides the following necessary and sufficient conditions for a condition being a clinical disease:

(a) the condition causes some harm or deprivation of benefit to the person as judged by the standards of the person's culture (the value criterion);

(b) the condition results from an internal mechanism performing its natural function at a harm-causing level of efficiency (that is, a level of efficiency that is bad for the individual), 'wherein a natural function is an effect that is part of the evolutionary explanation of the existence and structure of the mechanism (Wakefield's explanatory criterion), $^{5(19)}$ 
In this way, Smart avoids the objection that a suitable account of dysfunction cannot be provided (since 'dysfunction' does not feature in the view), whilst maintaining Wakefield's position that an account of clinical disease should have both a value criterion and an explanatory criterion.

\section{(c) Cooper's Tripartite Account of Disease}

The final account of disease we outline here is Cooper's value-laden concept of clinical disease. ${ }^{6}$ Cooper does not include an explanatory criterion, nor does she invoke any biostatistical considerations. Her view is through and through normative, focusing on the supposedly harm-causing nature of disease, where harmfulness is to be interpreted as harmful to the individual (as opposed to the state etc.).

Cooper believes that 'by disease we mean a condition that is a bad thing to have, that is such that we consider the afflicted person to have been unlucky, and that can potentially be medically treated'. The first is a harm-criterion similar to that found in Wakefield, directed at the beliefs and desires of the patient. This is important, since a condition deemed harmful by one patient might not be deemed harmful to another. In this way, the same physiological condition can be a disease for one patient and not for another (for example, sterility). The second condition is designed to distinguish diseases from conditions that are 'unpleasant but normal, for example teething'. ${ }^{6(271)}$ The third condition is there to distinguish between diseases, and other states that are both unlucky and unpleasant, such as divorce, financial difficulties, and so on.

This view has been criticised recently on the grounds that counterexamples are rife. For example, Smart asks us to imagine someone requesting 'peace and love' to be tattooed on her arm in Chinese symbols, but unbeknownst to her, is tattooed with the symbols for 'I hate China', instead. This satisfies all three criteria (it is unlucky, a bad thing to have, and is 
medically treatable), but it does not count as a disease. As it stands Cooper's view looks problematic, but it unquestionably identifies features that intuitively form part of the concept of disease.

All the accounts of disease we have considered face difficulties. Perhaps some can be resolved. Perhaps others are doomed to failure. In this paper, however, we do not intend to support one view over the others. We believe that each view has a contribution to make to the debate about 'what counts as disease', and furthermore, we believe that careful consideration of these analyses can help inform the medical sciences as to which conditions we should consider normal and healthy, which are pathological states but not clinical diseases, and which conditions are both pathological and clinical diseases. In the next section we apply each conceptual analysis to CKD, focussing in particular on the early stages. In turn, we demonstrate that although stages 1-3 CKD might be deemed pathological (at least in some cases), it does not count as a clinical disease under any of the conceptual analyses we have discussed.

\section{$4 \quad$ Chronic Kidney Disease}

The concepts of disease provided by Wakefield, Cooper and Smart, pertain specifically to clinical diseases; that is, to the concept of disease as it is employed by patient-facing clinicians. This contrasts with the theoretical concepts of disease (or the concept of 'pathological condition') provided by Boorse and Schwartz. In this section, looking in turn at each of the conceptions we have outlined, we focus on CKD, and in particular CKD stage 3 and stage 5 , questioning whether each should count as a pathological condition and/or as a clinical disease, as appropriate.

\subsection{Chronic Kidney Disease and the Theoretical Accounts of Disease}




\section{Chronic Kidney Disease and Boorse’s Biostatistical Account}

Let us recall BST: the view that a patient is diseased when a physiological subsystem is performing subnormally relative to her reference class (reference classes being determined by age, sex, and species-type). In the context of diagnoses based on Table 1, ascertaining whether an individual's kidney is performing subnormally for his or her reference class requires (i) the GFR for that patient; (ii) data showing the distribution of glomerular filtration rates across age groups, stratified by sex; (iii) determination of what GFR quantity demarcates the normal from the subnormal for that reference class. As we have seen, (iii) is subject to the line-drawing problem, but prima facie one should accept that this line could drop as the average GFR for the reference class drops. ${ }^{17}$

Coresh et al published the following data (see table 2 below) on the US adult population. ${ }^{18}$ We shall assume (again, for the sake of illustration), that the samples from the US population are representative of the global reference classes.

\section{Insert table 2 here}

Following Coresh et al, let us take the age groups 20-39, 40-59,60-69, and 70+ to be the reference classes (although the published age-group data does not differentiate between male and female participants, one can see that overall, the distribution of the male participants' kidney-function fairly closely resembles that of the female participants. We thus assume that the sex criterion of Boorse's reference classes plays only a small role in the case of CKD).

It is immediately apparent that there is no threshold definition such that CKD defined by GFR alone is a disease according to BST. For Boorse's definition of disease, any GFR threshold would have to be dependent on at least age and perhaps sex and ethnic group. The 
current definitions, being uniform across age, result in the inclusion in CKD stage 3 of many individuals whose GFR is normal for their reference class and hence who are not diseased by BST. By contrast CKD stage 5 is clearly a disease by BST, since there is no reference class in which stage $5\left(\mathrm{GFR}<15 \mathrm{~mL} / \mathrm{min} / 1.73 \mathrm{~m}^{2}\right)$ or even stage $4\left(\mathrm{GFR} 15-29 \mathrm{~mL} / \mathrm{min} / 1.73 \mathrm{~m}^{2}\right)$ is normal.

This also highlights a common objection to BST, namely, that mere age changes can affect one's health status ${ }^{17}$; for example, according to BST, when turning 40 years of age and assuming the $86^{\text {th }}$ percent threshold, those in the $87^{\text {th }}$ percentile of functional efficiency in the 20-39 year old reference class would, without any physiological changes, suddenly become healthy, since they would now fall within the 86 percentile of their new reference class.

Chronic Kidney Disease and Schwartz's Negative Consequences Criterion

Whether or not CKD counts as a pathological condition under BST depends on where pathologists suppose the line demarcating healthy and diseased kidneys should be drawn. The benefit of BST when it comes to CKD, is that wherever the line is drawn, the level of functional efficiency necessary for healthy kidneys for those in older reference classes is less than the level of functional efficiency needed for healthy kidneys in younger reference classes. This coheres with what clinicians take to be relevant when examining their patients. It does not cohere well with the current CKD classification system, however, according to which the majority of people over the age of 60 suffer from stage 2 CKD or worse.

Schwartz builds on Boorse's BST to provide a means of judging where 'the line' should be drawn, independently of medical definitions of token diseases (or at least, that is his intention). It is through Schwartz's account, then, that we demonstrate why CKD defined 
by decreased GFR alone should not be classed as pathological according to the biostatistical conceptions of pathological condition.

As we saw earlier, Schwartz attempts to resolve the line-drawing problem by introducing a negative consequences criterion, whereby the line demarcating health and disease states is to be drawn where there are 'effects that significantly diminish [the ability to] carry out an activity that is generally standard in the species and has been for a long

period of time'. ${ }^{16(379)}$ Schwartz recognises the need to provide at least some method of determining what is 'subnormal'. So where, according to Schwartz's negative consequences criterion, should one draw the line in the case of CKD?

Table 1 indicates that stage 5 CKD is a disease under Schwartz's account, being associated with severe harms. Stage 4 may manifest less severe harms such as fatigue and back pain ${ }^{19}$, but stage 3 is asymptomatic. The harms associated with stage 3 are an increased risk of progression to stages 4 and 5, and an increased risk of other conditions that may diminish the ability to carry out a standard activity. Thus CKD stage 3 is not a disease, in this account, but a risk factor for diseases including stage 5 CKD, acute kidney injury, and heart disease.

\subsection{Decreased GFR and The Clinician's Concept of Disease}

Disease as Harmful Dysfunction, Disease as Harmful Function, and Chronic Kidney Disease

Both Wakefield and Smart's accounts of disease requires two criteria to be fulfilled, a value criterion and an explanatory criterion. Again, stage 5 CKD clearly satisfies the value criterion 
for all reference classes, but it is not so obvious that the same is true of earlier stages, and in particular CKD stage 3 which is asymptomatic.

For a condition to qualify as a disease, the biostatistical theories require physiological subsystems to function subnormally (Boorse), or at a level preventing an organism from performing tasks standard for its reference class (Schwartz). In place of Schwartz's negative consequence criterion, Wakefield suggests that disease involves an inability of some internal mechanism to perform its natural function (and Smart, that diseases involve harm-causing levels of functional efficiency). However, kidneys often adequately perform their natural function until stage 5 . Where there is a "harm" associated with earlier stages of CKD, then, it arguably pertains primarily to the increased risk of other pathological conditions such as heart disease. Although by the very nature of the concept of "risk", a patient does not experience any symptoms, we believe that the increased risk caused by lower GFR can nevertheless be a form of harm. This is particularly evident in younger patients, since the increased risk of heart disease can significantly affect life expectancy. In the case of elderly patients, whether this risk-increase qualifies as harmful is less clear, since life expectancy is less affected.

In section 3.ii we outlined Wakefield's view that to be diseased, the physiological subsystem/trait must (i) fail to perform its natural function (dysfunction), and (ii) cause harm. Even if we agree that increasing the risk of disease (e.g., heart disease) is a form of harm, at stage 3 CKD the kidney itself is often not "dysfunctioning” in the sense that it is failing to perform its natural function: rather, it is performing, at a lower level than usual, but nevertheless sufficiently well at present (noting that the state is asymptomatic). Smart's account is less restrictive. It grants that physiological subsystems might perform their natural function adequately for the short term / immediate present whilst still functioning at a harmcausing level of efficiency. Although in most cases the kidney at stage 3 is not dysfunctioning, the degree of efficiency at which it operates (defined here in terms of GFR) 
raises the risk of heart disease relative to patients with more efficient kidney-function. Smart's account thus allows some patients with stage 3 CKD to be diseased (particularly younger patients), whereas Wakefield's does not.

\section{Chronic Kidney Disease and Cooper's Tripartite Account}

As outlined previously, Cooper argues that diseases are bad for the patient, that the patient is unlucky to have that condition, and that the condition is potentially medically treatable. In the case of CKD, we could argue that the potential medical intervention criterion is met for all stages of CKD under consideration: it is plausible that decreased GFR could be medically treated (and indeed interventions already exist in some circumstances, such as change of medication class in patients taking anti-hypertensives) It is the second of Cooper's three conditions - 'considered unlucky' - that is hardest to apply to CKD. As tables 1 and 2 indicate, given a life expectancy of 70+ it is statistically likely that one will satisfy the current criteria for early stage CKD during one’s lifetime. A 70-year-old would be hard pressed to claim bad luck just in virtue of having stage $1 \mathrm{CKD}$, since her kidneys would be outperforming the vast majority of those in her reference class. On the other hand, a young patient with decreased GFR would be warranted in claiming 'bad luck'. According to Cooper's tripartite account, then, decreased GFR would count as a disease for younger patients (but not necessarily for the elderly, if the increased risk of heart disease does not significantly affect their life expectancy).

\section{Conclusions}

We have considered CKD defined by decreased GFR in the context of five concepts of disease (two analyses of the theoretical concept of disease, or 'pathological condition', and three analyses of the clinician's concept of disease). Decreased GFR in older patients, and 
hence CKD stage 3, does not necessarily satisfy the criteria for disease under any of these analyses. There are essentially two reasons for this: first, it is statistically normal for the elderly to suffer from decreased GFR; second, decreased GFR need not be seen as harmful in the case of older reference classes. It seems reasonable, then, to conclude that CKD in older patients is not likely to be classed as a disease under any plausible analysis of the concept.

Some philosophers of medicine (e.g. Hesslow ${ }^{9}$ ) have argued that the project of analysing the concept of disease is unproductive, and has no value in the medical sciences. The answer to the question 'what is disease', they argue, should not be seen as interesting to medical practitioners, since it should not affect clinical decision making. When laymen wish to describe their state of physical or psychological wellbeing, both the term 'health' and the term 'disease' are useful instruments, but the medical sciences should not be concerned about whether 'disease' implies bad luck, the possibility of medical treatment, subnormal function, and so on.

We disagree with Hesslow. Analysing the concept of disease matters since clinical and theoretical concepts of disease inform how physiological conditions are classified, and whether a condition is labelled a disease matters. All analyses of the concept of disease presented in this paper include either reference to subnormal part function, some form of 'harm' criterion, or both, so it is unsurprising that being diagnosed with a disease has psychological consequences. Although causing patients distress in this way is necessary when the patient is truly sick, misclassifying as disease a condition such as stage 3 CKD in the elderly is not without consequences. We have argued elsewhere that alternative terminology could avoid the word disease without losing the ability to discuss risk, interventions and consequences with patients. ${ }^{20}$

Our analysis is concerned with chronic kidney disease defined by GFR below 60 $\mathrm{ml} / \mathrm{min} / \mathrm{m}^{2}$. Direct measurement of GFR requires radioactive isotope methods and so 
equations for estimating GFR from venous serum creatinine have been published. ${ }^{20,21}$ Our analyses of health states defined by a biomarker hold, and remain valid, regardless of the accuracy of the biomarker, and the use of estimated GFR rather than measured GFR in clinical practice does not affect our conclusions.

Our analysis illustrates that attention to philosophical analyses of the disease-concept can help resolve debates about "overmedicalization”. ${ }^{22}$ Similar analyses could inform the debate about whether a condition such as hypertension or "prediabetes" is to be considered disease or risk factor. In other cases, it could advance a debate by highlighting important distinctions: for example, between diabetes identified by symptoms and diabetes defined by biomarkers alone. ${ }^{\mathrm{i}}$

\section{References}

1. Boorse, C. On the Distinction between Disease and Illness. Philosophy and Public Affairs. 1975; 5(1): 49-68.

2. Boorse, C. Health as a Theoretical Concept. Philosophy of Science. 1977; 44(4): 542-573.

3. Boorse, C. A Rebuttal on Health. In: Humber J.M., Almeder R.F. (eds). What is Disease? Totowa, NJ: Humana Press Inc; 1997: 1-134 
4. Boorse, C. A Second Rebuttal on Health. Journal of Medicine and Philosophy. 2014; 39(6): 683-724.

5. Smart, B.T.H. Concepts and Causes in the Philosophy of Disease. Basingstoke: Palgrave Macmillan, 2016.

6. Cooper, R. Disease. Studies in History and Philosophy of Science Part C: Studies in History and Philosophy of Biological and Biomedical Sciences. 2002; 33(2): 263-282. Doi: 10.1016/S0039-3681(02)00018-3

7. Wakefield, J. The Concept of Mental Disorder: On the Boundary between Biological Facts and Social Values. American Psychologist. 1993; 47: 373-388

8. Ananth, M. In Defense of an Evolutionary Concept of Health: Natures, Norms and Human Biology. Aldershot, UK: Ashgate Publishing Limited, 2008.

9. Hesslow, G. Do We Need a Concept of Disease? Theoretical Medicine. 1993; 14(1): 1-14 10. Miyaji, N.T. The Power of Compassion: Truth-Telling Among American Doctors in the Care of Dying Patients. Social Science and Medicine. 1993; 36(3): 249-264 11. O'Hare, A.M., Choi, A.I., Bertenthal, D., Bacchetti, P., et al. Age affects outcomes in chronic kidney disease. Journal of the American Society of Nephrology. 2007; 18(10): 27582765.

12. Stevens, R.J., Evans, J., Oke, J., Smart, B., Hobbs, R., Holloway, E., Horwood, J., Judd, M., Locock, L., McLellan, J. and Perera, R., 2018. Kidney age, not kidney disease. Canadian Medical Association Journal.

13. US National Kidney Disease Foundation. NKF KDOQI guidelines. http://www2.kidney.org/professionals/KDOQI/guidelines_ckd/p4_class_g1.htm. Published 2002. Accessed February 7, 2018 
14. de Lusignan S, Tomson C, Harris K, et al. UK Prevalence of Chronic Kidney Disease for the Adult Population Is 6.76\% Based on Two Creatinine Readings. Nephron Clinical Practice 2012;120(2):c107-c07

15. Hill, N.R., Fatoba, S.T., Oke, J.L., Hirst, J.A., O’Callaghan, C.A., Lasserson, D.S. and Hobbs, F.R., 2016. Global prevalence of chronic kidney disease-a systematic review and meta-analysis. PloS one, 11(7), p.e0158765.

16. Schwartz, P. H. Natural Selection, Design, and Drawing a Line. Philosophy of Science. 2007; 74(3): 364-385

17. Guerrero, D.J. On a Naturalist Theory of Health: A Critique. Studies in History of Philosophy of Biological and Biomedical Sciences. 2010; 41(3): 272-8.

18. Coresh, J., Astor, B. C., Greene, T., Eknoyan, G., \& Levey, A. S. Prevalence of chronic kidney disease and decreased kidney function in the adult US population: Third National Health and Nutrition Examination Survey. American journal of kidney diseases. 2003; 41(1): $1-12$.

19. National Collaborating Centre for Chronic Conditions (Great Britain), 2008. Chronic kidney disease: national clinical guideline for early identification and management in adults in primary and secondary care. Royal College of Physicians.

20. Levey, A.S., Stevens, L.A., Schmid, C.H., Zhang, Y.L., Castro, A.F., Feldman, H.I., Kusek, J.W., Eggers, P., Van Lente, F., Greene, T. and Coresh, J., 2009. A new equation to estimate glomerular filtration rate. Annals of internal medicine, 150(9), pp.604-612.

21. Levey, A.S., Coresh, J., Greene, T., Stevens, L.A., Zhang, Y.L., Hendriksen, S., Kusek, J.W. and Van Lente, F., 2006. Using standardized serum creatinine values in the modification of diet in renal disease study equation for estimating glomerular filtration rate. Annals of internal medicine, 145(4), pp.247-254. 
22. Doshmangir, P., Doshmangir, L., and Shaghaghi, R. Exploring Factors Influencing Over-

Medicalization: A Scoping Review. BMJ Open, 7(Suppl 1), pp. bmjopen-2016

\section{Tables:}

Table 1: US National Kidney Foundation (NKF) Kidney Disease Outcomes Quality Initiative (KDOQI) definition and classification of stages of chronic kidney disease (columns 1-3), and remarks on symptomatic status (column 4).

\begin{tabular}{|c|c|c|c|}
\hline \multicolumn{3}{|c|}{$\begin{array}{l}\text { KDOQI Definition and classification of stages of } \\
\text { chronic kidney disease* }\end{array}$} & \multirow[t]{2}{*}{ Remarks } \\
\hline $\begin{array}{l}\text { CKD } \\
\text { stage }\end{array}$ & Description & $\begin{array}{c}\text { GFR } \\
\left(\mathrm{mL} / \mathrm{min} / 1.73 \mathrm{~m}^{2}\right)\end{array}$ & \\
\hline 1 & $\begin{array}{l}\text { Kidney damage with } \\
\text { normal or elevated } \\
\text { GFR }\end{array}$ & $>=90$ & $\begin{array}{l}\text { Asymptomatic except: } \\
\text { Increased risk of cardiovascular disease } \\
\text { Increased risk of stage } 2 \text { CKD and beyond }\end{array}$ \\
\hline 2 & $\begin{array}{l}\text { Kidney damage with } \\
\text { mild decreased GFR }\end{array}$ & $60-89$ & $\begin{array}{l}\text { Asymptomatic except: } \\
\text { Associated with a greater risk of } \\
\text { cardiovascular disease than stage } 1 \text {, but } \\
\text { less than stage } 3 \text { CKD } \\
\text { Increased risk of stage } 3 \text { CKD and beyond }\end{array}$ \\
\hline 3 & $\begin{array}{l}\text { Moderate decreased } \\
\text { GFR }\end{array}$ & $30-59$ & Asymptomatic except: \\
\hline
\end{tabular}




\begin{tabular}{|c|c|c|l|}
\hline & & & $\begin{array}{l}\text { Associated with a greater risk of } \\
\text { cardiovascular disease than stage 2, but } \\
\text { less than stage 4 CKD } \\
\text { Increased risk of stage 4 CKD and beyond }\end{array}$ \\
\hline 4 & $\begin{array}{c}\text { Severe decreased } \\
\text { GFR }\end{array}$ & $15-29$ & $\begin{array}{l}\text { Asymptomatic except: } \\
\text { Associated with a greater risk of } \\
\text { cardiovascular disease than stage 3, but } \\
\text { less than stage 5 CKD }\end{array}$ \\
\hline 5 & Kidney failure & $<15$ (or dialysis) & $\begin{array}{l}\text { End stage CKD } \\
\text { Associated with a greater risk of } \\
\text { cardiovascular disease than stage 4 CKD } \\
\text { Kidneys malfunctioning such that dialysis } \\
\text { of transplant is needed to stay alive. }\end{array}$ \\
\hline
\end{tabular}

* 2002 Guidelines; from

http://kidneyfoundation.cachefly.net/professionals/KDOQI/guidelines_ckd/index.htm.

Table 2: Prevalence of Normal and Decreased Kidney Function (GFR Categories) by Demographics and Clinical Characteristics in Adults Aged 20 Years and Older, NHANES III, 1988 to 1994 [16, table 1]

\begin{tabular}{|c|c|c|c|c|c|c|}
\hline & \multicolumn{2}{|c|}{ Overall } & \multicolumn{4}{|c|}{ Prevalence of GFR Category $\left(\mathrm{mL} / \mathrm{min} / 1.73 \mathrm{~m}^{2}\right)$} \\
\hline & $\begin{array}{l}\text { No of } \\
\text { participants }\end{array}$ & $\begin{array}{l}\text { US } \\
\text { Population }\end{array}$ & $\begin{array}{l}\text { Normal } \\
(90+)\end{array}$ & $\begin{array}{l}\text { Mild (60- } \\
90)\end{array}$ & $\begin{array}{l}\text { Moderate } \\
(30-59)\end{array}$ & $\begin{array}{l}\text { Severe } \\
(15-29)\end{array}$ \\
\hline Total & $15,600^{*}$ & 100,0 & $64.3(0.8)$ & $31.2(0.8)$ & $4.3(0.2)$ & $\begin{array}{l}0.20 \\
(0.03)\end{array}$ \\
\hline \multicolumn{7}{|l|}{ Sex } \\
\hline Men & 7,267 & $47.6(0.4)$ & $65.8(0.9)$ & $30.7(0.9)$ & $3.4(0.3)$ & $\begin{array}{l}0.18 \\
(0.05)\end{array}$ \\
\hline Women & 8,333 & $52.4(0.4)$ & $63.0(1.1)$ & $31.7(1.0)$ & $5.1(0.4)$ & $\begin{array}{l}0.23 \\
(0.05)\end{array}$ \\
\hline \multicolumn{7}{|l|}{ Age (y) } \\
\hline $20-39$ & 6,263 & $46.1(1.0)$ & $86.0(0.9)$ & $13.7(0.9)$ & $\begin{array}{l}0.21 \\
(0.07)\end{array}$ & $\mathrm{X}$ \\
\hline $40-59$ & 4,182 & $31.2(0.6)$ & 55.7 (1.1) & $42.4(1.1)$ & $1.8(0.3)$ & $\mathrm{X}$ \\
\hline $60-69$ & 2,190 & $11.3(0.5)$ & $38.6(1.4)$ & $53.8(1.8)$ & $7.1(0.9)$ & $\begin{array}{l}0.46 \\
(0.21)\end{array}$ \\
\hline
\end{tabular}




\begin{tabular}{|c|c|c|c|c|c|c|}
\hline $70+$ & 2,965 & $11.3(0.7)$ & $25.6(1.3)$ & $48.5(1.1)$ & $24.6(1.1)$ & $1.3(0.3)$ \\
\hline \multicolumn{7}{|l|}{ Race } \\
\hline $\begin{array}{l}\text { Non- } \\
\text { Hispanic } \\
\text { white }\end{array}$ & 6,635 & $76.4(1.3)$ & $59.7(1.0)$ & $35.2(0.9)$ & $4.8(0.3)$ & $\begin{array}{l}0.21 \\
(0.03)\end{array}$ \\
\hline $\begin{array}{l}\text { Non- } \\
\text { Hispanic } \\
\text { Black }\end{array}$ & 4,163 & $10.9(0.6)$ & $79.2(1.1)$ & $17.4(0.9)$ & $3.1(0.2)$ & $\begin{array}{l}0.25 \\
(0.08)\end{array}$ \\
\hline $\begin{array}{l}\text { Mexican } \\
\text { American }\end{array}$ & 4,185 & $5.1(0.4)$ & $85.4(0.6)$ & $13.5(0.6)$ & $1.0(0.1)$ & $\mathrm{X}$ \\
\hline Other & 617 & $7.6(0.8)$ & $75.6(3.3)$ & $21.9(2.9)$ & $2.2(0.2)$ & $\mathrm{X}$ \\
\hline \multicolumn{7}{|c|}{ Diabetes mellitus diagnosis } \\
\hline No & 14,372 & $95.0(0.3)$ & $65.4(0.9)$ & $30.7(0.8)$ & $3.7(0.2)$ & $\begin{array}{l}0.17 \\
(0.03)\end{array}$ \\
\hline Yes & 1,211 & $5.0(0.3)$ & $44.5(2.0)$ & $40.4(1.9)$ & $14.2(1.3)$ & $\begin{array}{l}0.92 \\
(0.31) \\
\end{array}$ \\
\hline \multicolumn{7}{|c|}{ Hypertension } \\
\hline No & 10,707 & $75.9(0.8)$ & $71.5(0.9)$ & $26.9(0.8)$ & $1.5(0.1)$ & $\mathrm{X}$ \\
\hline $\begin{array}{l}\text { Yes, no } \\
\text { medication }\end{array}$ & 2,340 & $11.5(0.5)$ & $48.5(1.5)$ & $43.2(1.5)$ & $7.9(0.7)$ & $\begin{array}{l}0.34 \\
(0.13)\end{array}$ \\
\hline $\begin{array}{l}\text { Yes, on } \\
\text { medication }\end{array}$ & 2,553 & $12.6(0.5)$ & $35.6(1.5)$ & 46.0 (1.9) & $17.5(0.9)$ & $\begin{array}{l}0.94 \\
(0.22)\end{array}$ \\
\hline
\end{tabular}

Coresh et al. 2003. Prevalence of Chronic Kidney Disease and Decreased Kidney Function in the Adult US Population: Third National Health and Nutrition Examination Survey. American Journal of Kidney Diseases. Vol 41, No 1 (January), pg 6. Awaiting Permissions

Figure Legends

\section{Figure 1: The Biostatistical Account}

Schwartz, P. H. Natural Selection, Design, and Drawing a Line. Philosophy of Science. 2007; 74(3): 373

Figure 2: The Frequency and Negative Consequences Account

Schwartz, P. H. Natural Selection, Design, and Drawing a Line. Philosophy of Science. 2007; 74(3): 378 
${ }^{\mathrm{i}}$ We would like to thank Michael Talibard for his comments on early drafts of this paper. 